\title{
Model for simulation of the mechanical behavior of a porous shape memory alloy with a non-ordered structure
}

\author{
E. N. Iaparova ${ }^{\dagger}$ A. E. Volkov, M. E. Evard \\ †elizaveta_iaparova@outlook.com
}

Saint Petersburg State University, 7/9 Universitetskaya Emb., St. Petersburg, 199034, Russia

\begin{abstract}
A model for simulation of the mechanical properties of porous NiTi shape memory alloy samples (SMA) with high through porosity has been proposed. Such samples are obtained from nickel and titanium powders by self-propagating hightemperature synthesis under specially selected technological conditions. The structure of the samples corresponds to a set of ligaments without a clearly defined orientation of the pore channels. In this work, a study of microphotographs of porous NiTi samples with a porosity of $60 \%$ has been carried out. Basing on this study such a porous material has been approximated by a beam structure consisting of horizontal beams supported by vertical curved beams. A specially developed technique of finding the geometric parameters of this beam structure was used for its characterization. The object for modeling determined in this way provides the opportunity to take into account the basic structural features of the sample. The strain of the porous sample is then calculated with the use of the methods of the strength of materials by calculating the displacements of all structural elements. The constitutive relations of the SMA microstructural model have been used to describe the SMA deformation. This model proved to be an efficient tool for simulation of the functional and mechanical behavior of a solid SMA under various thermal and mechanical loadings. The deformation curves of porous NiTi under compression at different temperatures corresponding to the martensitic and to the austenitic state of the SMA have been calculated. The results of the simulation have shown good agreement with the experimental data.
\end{abstract}

Keywords: modeling, shape memory alloys, porous NiTi.

УДК: 538.91

\section{Модель для расчета механического поведения пористого сплава с памятью формы с неупорядоченной структурой}

\author{
Япарова Е.Н. ${ }^{\dagger}$ Волков А.Е., Евард М.Е. \\ Санкт-Петербургский государственный университет, Университетская наб., 7/9, С.-Петербург, 199034, Россия
}

\begin{abstract}
Предложена модель для расчета механических свойств образцов с высокой сквозной пористостью из сплава с памятью формы (СПФ) NiTi. Такие образцы получаются из порошков никеля и титана методом самораспространяющегося высокотемпературного синтеза, проведенного при специально подобранных технологических условиях. Структура образцов представляет собой набор межпоровых перегородок без четко выраженной ориентации поровых каналов. В данной работе было проведено исследование микрофотографий пористых образцов NiTi с пористостью $60 \%$. На основании этого исследования такой пористый материал был аппроксимирован балочной структурой, состоящей из горизонтальных балок, поддерживаемых вертикальными изогнутыми балками. Для его характеристики была использована специально разработанная методика определения геометрических параметров рассматриваемой балочной конструкции. Определенный таким образом объект для моделирования дает возможность учесть основные структурные особенности образца. Деформация пористого образца затем рассчитывается с использованием методов сопротивления материалов путем расчета смещений всех элементов конструкции. Использованы определяющие соотношения микроструктурной модели СПФ, которая хорошо зарекомендовала себя при расчете функциональномеханического поведения СПФ при различных термических и механических нагрузках. Выполнен расчет диаграмм деформирования пористого $\mathrm{NiTi}$ при сжатии при разных температурах, соответствующих мартенситному и аустенитному состоянию СПФ. Результаты моделирования показали хорошее согласие с экспериментальными данными.
\end{abstract}

Ключевые слова: моделирование, сплавы с памятью формы, пористый NiTi. 


\section{Introduction}

Shape memory alloys (SMA) form a class of smart materials with specific mechanical behavior controlled by stress and temperature. Most widely used SMA are NiTi-based alloys due to their high physical and mechanical characteristics and the shape memory effect $[1,2]$. Porous NiTi specimens exhibit pseudoelastic deformation behavior and strain recovery on heating, and have high damping capacity coupled with permeability specific to highly porous materials. All these features make porous NiTi useful for many applications in engineering and medicine $[3,4]$. In order to simulate the deformation of porous SMA, one needs an accurate but simple model.

Almost all currently available works devoted to strain calculations of porous SMA are based on the microstructural or macroscopic phenomenological model of SMA [5-12]. It is known that the structural features of pore channels strongly affect the deformation behavior of the samples [13], and because of these models, which take into account the effect of pore channels on mechanical behavior only in an indirect way, may be insufficient. Thus, it is necessary to develop methods for predicting the behavior of a porous SMA, which can both describe the deformation behavior of a solid SMA and take into account the features of the porous structure. An attempt to develop such model is undertaken in the present work.

\section{Modeling}

For accurate modeling of porous SMA, the shape and dimensions of pore channels and ligaments must be considered. In the present work, this was done by analyzing metallographic sections of the sample. The microstructure of highly porous NiTi samples obtained by self-propagating high temperature synthesis consists of many interconnected interpore ligaments of various sizes. These ligaments often do not have a distinct orientation relatively to the sample axis (Fig. 1a). The morphology of the sample with such a disordered orientation of the pore channels was approximated by a structure resembling a flat slotted spring (Fig. 1b), in which beams representing interpore ligaments oriented perpendicular to the sample axis are connected to adjacent layers by vertical curved beams. It is assumed that for the implementation of the model one needs considering

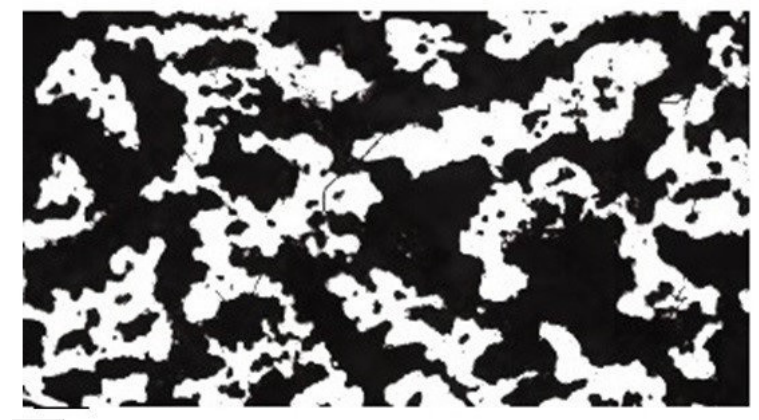

a several types of slotted springs with different values of geometric parameters (dimensions). Parameters related to a particular type will be denoted by index $i$, the value of which corresponds to the number of the type. One can consider each slotted spring as built of structural elements, each including one horizontal beam and one curved vertical beam (Fig. 2) (each vertical beam shown in Fig. 2 belongs to two adjacent structural elements).

To avoid solving a complicated boundary-value problem, two hypotheses are accepted: (1) the deformation behavior of each beam composing a beam structure can be represented by its mostly strained region; and (2) Bernoulli's plane-sections hypothesis is true, so that any vertical curved beam is shaped as a circular arc during the entire deformation process. Thus, to simulate the deformation of such a construction, one has to solve two problems: compression of a curved beam along its axis and bending of a beam by a distributed load $q$, the beam being supported at its ends (Fig. 2). The values of the displacement of the ends of the vertical beam form boundary conditions for the corresponding horizontal beam.

Consider a porous specimen loaded by an average compressive stress $\sigma$ with area of the cross-section $S$ and porosity $p$. We replace this specimen by a cascade of slotted springs belonging to all considered types. The maximum stress $s_{i}$ in the horizontal beam of $i$-th type can be calculated within the frames of the strength of materials as it was shown in [14]:

$$
s_{i}=\frac{3 P\left(l_{i}-a_{i}+\frac{a_{i}^{2}}{3 l_{i}}\right)}{4 b_{s i} h_{s i}^{2}},
$$

where $l_{i}, b_{s i}$ and $h_{s i}$ are the length, width and height of a horizontal beam of the $i$-th type, $a_{i}$ is the length, along which the load is distributed with the linear density $q$. In Eq. $1 P=q a_{i}$

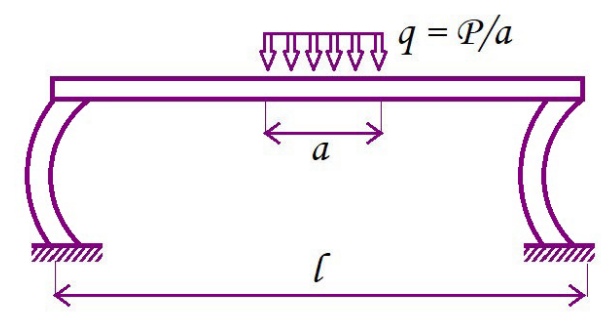

Fig. 2. Horizontal beam under a distributed load.

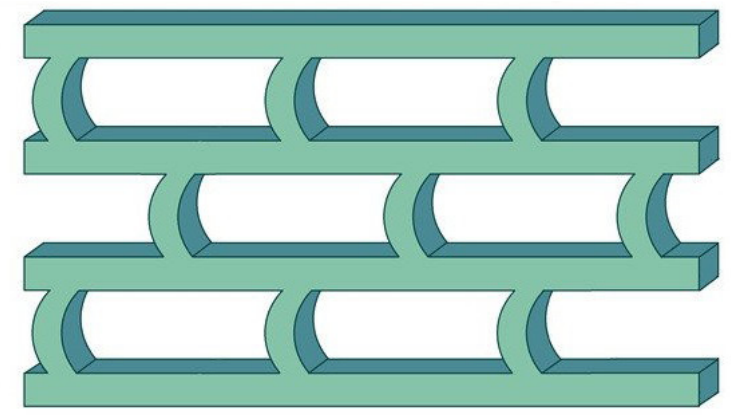

b

Fig. 1. (Color online) Microphotograph of the studied porous NiTi produced by self-propagating high temperature synthesis (dark fields are voids) (a); a flat slotted spring composed of the structural elements of one type (b). 
is the force applied to one horizontal beam and originating from the average stress in the porous sample:

$$
P=\frac{\sigma S(m-1+p)^{2}}{(m-1)^{2}},
$$

where $m$ is the number of vertical curved beams falling to the cross-section of the sample.

The displacement $v_{i}$ produced by a structural element consists of the beam deflection $w_{i}$ in its center and the displacement $u_{i}$, which is the decrease of the distance between the ends of the curved vertical beam:

$$
v_{i}=w_{i}+u_{i}
$$

The deflection $w_{i}$ within the frames of the strength of materials assumptions and hypotheses (1) and (2) is related to the strain $e_{i}$ in the most strained section of the beam. In this work $e_{i}$ is calculated by the microstructural model [15], though also any other model could be used. The displacement $u_{i}$ produced by a vertical curved beam is easily calculated as the difference between the lengths of the chords of the curved beam before and after the deformation. Thus:

$$
\begin{gathered}
w_{i}=\frac{e_{i}\left(-2 l_{i}^{3}+2 l_{i} a_{i}^{2}-a_{i}^{3}\right)}{24 h_{i}\left(l_{i}-a_{i}+\frac{a_{i}^{2}}{3 l_{i}}\right)}, \\
u_{i}=2 R_{i} \sin \frac{\varphi_{i}}{2}-2 R_{i}^{\prime}\left(\varepsilon_{i}\right) \sin \frac{\varphi_{i}^{\prime}\left(\varepsilon_{i}\right)}{2},
\end{gathered}
$$

where $R_{i}$ and $\varphi_{i}$ are the radius and central angle of the vertical curved beam before deformation, $R_{i}^{\prime}$ and $\varphi_{i}^{\prime}$ are the radius and central angle after deformation, $\varepsilon_{i}$ is the maximum strain in the curved vertical beam. The dependences $R_{i}^{\prime}\left(\varepsilon_{i}\right)$ and $\varphi_{i}^{\prime}\left(\varepsilon_{i}\right)$ were also derived [16] within the frames of the hypotheses (1) and (2):

$$
R_{i}^{\prime}=\frac{R_{i} h_{i}}{2 \varepsilon_{i} R_{i} h_{i}}, \quad \varphi_{i}^{\prime}=\frac{R_{i} \varphi_{i}\left(\varepsilon_{i}+1\right)}{R_{i}^{\prime}} .
$$

Substituting the value of the displacements $w_{i}$ and $u_{i}$ from Eq. 4 into Eq. 3, the displacement produced by $i$-th structural element can be found. The stress in the curved beam is calculated within the framework of the strength of material:

$$
s_{i}=-\frac{P}{b_{i} h_{i}}+\frac{2 P\left(\frac{\varphi_{i}}{2}-\sin \frac{\varphi_{i}}{2}\right)\left(R_{i}-\frac{h_{i}}{\ln \frac{R}{R_{i}-h_{i}}}\right)}{\varphi_{i} S\left(R_{i}-\frac{h_{i}}{2}-\frac{h_{i}}{\ln \frac{R_{i}}{R_{i}-h_{i}}}\right)},
$$

where $b_{i}$ and $h_{i}$ are the width and the height of vertical curved beam cross-section. The strain $\varepsilon_{i}$ of a vertical beam is calculated using stress value from Eq. 6 and the equations of the microstructural model [15]. Finally, the strain of the sample $\mathrm{E}$ is determined by the ratio of the total displacement to the initial length of the sample

$$
\mathrm{E}=\frac{\sum_{i}\left(v_{i}\right)}{\sum_{i}\left(h_{i}+H_{i}\right)},
$$

where $H_{i}$ is the gap in the slotted spring of the $i$-th type (the distance between two parallel horizontal beams). If the displacement $v_{i}$ exceeds the value of $H_{i}$, it is supposed that the contribution of this structural element to the total strain is equal to the strain $\mathrm{E}$ of the elastic body under uniaxial compression.

\section{Results}

For simulation of the porous SMA behavior, measurements of the geometric parameters characterizing the pore structure have been performed. Using a LOMO optical microscope panoramic photograph of the sample with a porosity of $60 \%$ has been taken, and more than 200 direct measurements of the cross-section details have been carried out using the ImageExpertPro software. It was found very important to determine the modes of distributions of the equivalent beam structure geometrical parameters. An account of only their mean values affected the accuracy of the results.

For the numerical implementation of this model, 4 types of beam elements in the ratios $10: 3: 5: 1$ were selected. The corresponding values are presented in Table 1.

The following transformation temperatures were used for modeling: $M_{s}=72^{\circ} \mathrm{C}, M_{f}=57^{\circ} \mathrm{C}, A_{s}=92^{\circ} \mathrm{C}, A_{f}=107^{\circ} \mathrm{C}$, Young's moduli in the austenite state $E_{\mathrm{A}}=70 \mathrm{GPa}$ and in the martensitic state $E_{\mathrm{M}}=30 \mathrm{GPa}$, Poisson's ratio $v=0.33$ for the both states.

Fig. 3 a shows the simulated stress-strain diagrams of isothermal compression up to $350 \mathrm{MPa}$ with intermediate unloadings of the samples with a porosity of $60 \%$ in the martensitic state at temperatures 25,45 , and $65^{\circ} \mathrm{C}$. The dashed lines indicate the experimental curves [17]. The stress-strain diagrams for porous TiNi sample under compression in the austenitic state at temperature $160^{\circ} \mathrm{C}$ is shown in Fig. $3 \mathrm{~b}$. The curve indicated by the dashed line illustrates the experimental data [17], the solid line corresponds to the numerical results. The non-linear character of the theoretical curves is due to the non-simultaneous start of different deformation mechanisms in beams with different dimensions. In general, the theoretical approach gives a satisfactory description of the experimental data.

Table 1. Geometrical parameters selected for the numerical implementation of model.

\begin{tabular}{|c|c|c|c|c|}
\hline \multirow{2}{*}{ Parameter } & \multicolumn{4}{|c|}{ Type of structural element } \\
\cline { 2 - 5 } & 1 & 2 & 3 & 4 \\
\hline$R_{i}, \mathrm{~mm}$ & 0.15 & 0.2 & 0.3 & 0.4 \\
\hline$\varphi_{i}, \mathrm{rad}$ & 1.13 & 1.64 & 0.8 & 0.9 \\
\hline$h_{i}, \mathrm{~mm}$ & 0.03 & 0.07 & 0.05 & 0.04 \\
\hline$b_{i}, \mathrm{~mm}$ & 0.08 & 0.06 & 0.11 & 0.15 \\
\hline$l_{i}, \mathrm{~mm}$ & 0.2 & 0.3 & 0.15 & 0.7 \\
\hline$a_{i}, \mathrm{~mm}$ & 0.05 & 0.07 & 0.1 & 0.02 \\
\hline$h_{s i}, \mathrm{~mm}$ & 0.05 & 0.03 & 0.06 & 0.08 \\
\hline$H_{i}, \mathrm{~mm}$ & 0.1 & 0.15 & 0.5 & 0.25 \\
\hline$b_{s i}, \mathrm{~mm}$ & 0.08 & 0.06 & 0.11 & 0.15 \\
\hline
\end{tabular}



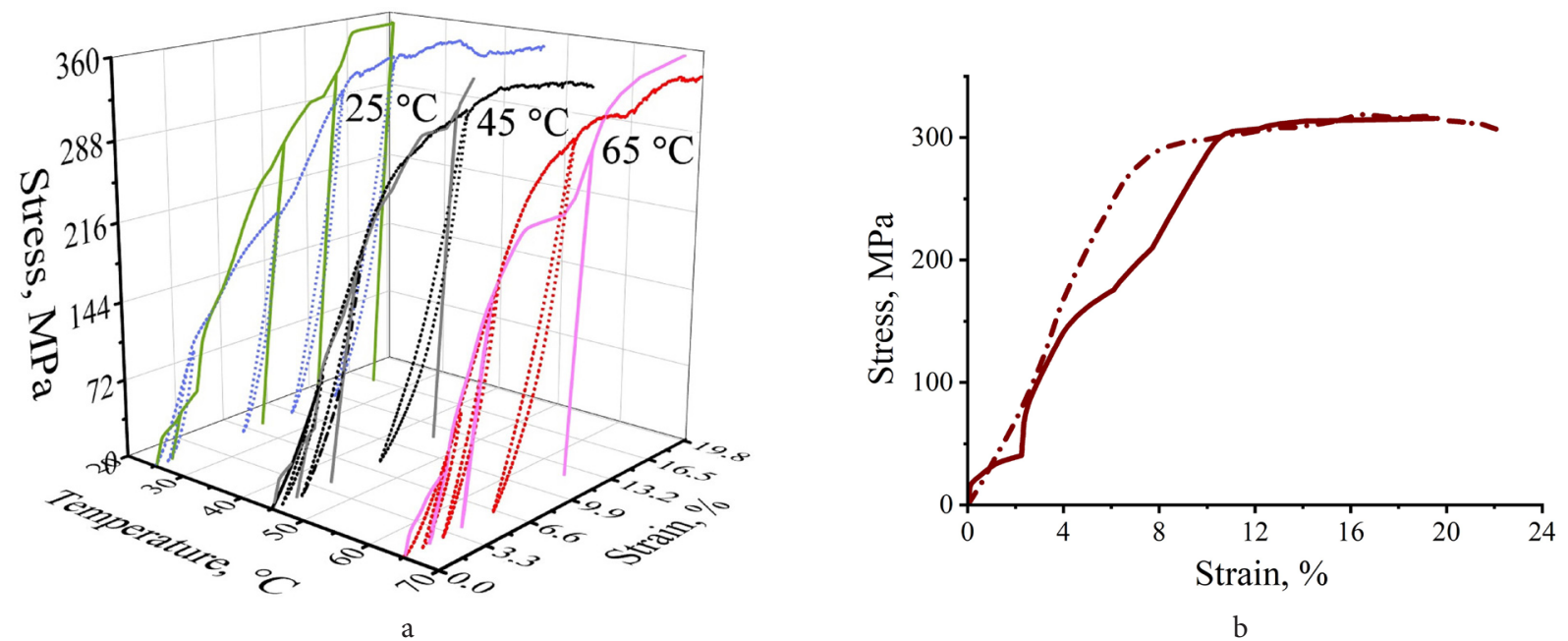

Fig. 3. (Color online) Stress-strain diagrams of compression of porous TiNi samples with porosity $60 \%$ in the martensitic (a) and austenite (b) states: calculation — solid lines; experiment [17] — dot lines.

\section{Conclusion}

The proposed approach, based on the theory of bent beams and the microstructural model of SMA, allows describing the deformation behavior of porous NiTi with a non-ordered structure under isothermal conditions in different phase states. The combination of a proper mechanical model and equations of the microstructural model is a good tool for the calculation of the deformation behavior of smart porous structures.

Acknowledgements. This research was supported by the Russian Foundation of Basic Research (grant 18-31-00461 and grant 18-01-00594).

\section{References}

1. E. Patoor, D.C. Lagoudas, P.B. Entchev, L.C. Brinson, X. Gao. Mech. Mater. 38 (5-6), 391 (2006). Crossref

2. J. Van Humbeeck. Mater. Sci.Eng. A. 273-275, 134 (1999). Crossref

3. M. Bram, M. Kohl, H.P. Buchkremer, D. Stover. J. Mater. Eng. Perform. 20 (4-5), 522 (2011). Crossref

4. M.H. Elahinia, M. Hashemi, M. Tabesh, S. B. Bhaduri. Prog. Mater. Sci. 57, 911 (2012). Crossref
5. M.A. Qidwai, P.B. Entchev, D.C. Lagoudas, V. G. DeGiorgi. Int. J. Solids Struct. 38 (48), 8653 (2001). Crossref

6. Y. Zhao, M. Taya. J. Appl. Mech. 74, 291 (2007). Crossref

7. M. Karamooz-Ravari, M. Kadkhodaei, A. Ghaei. J. Mater. Eng. Perform. 24 (10), 4096 (2015). Crossref

8. T. El Sayed, E. Gürses, A. Siddiq. Comput. Mater. Sci. 60, 44 (2012). Crossref

9. V. Sepe, F. Auricchio, S. Marfia, E. Sacco. Comput Mech. 57, 755 (2016). Crossref

10. M. Panico, L. C. Brinson. Int. J. Solids Struct. 45, 5613 (2008). Crossref

11. S. Nemat-Nasser, Y. Su, W. G. Guo, J. Isaacs. J. Mech. Phys. Solids. 53, 2320 (2005). Crossref

12. M. J. Ashrafi, J. Arghavani, R. Naghdabadi, F. Auricchio. J. Intel. Mat. Syst. Str. 27 (5), 608 (2016). Crossref

13. M. Kaya, N. Orhan, G. Tosun. Curr. Opin. Solid St. M. 14, 21 (2010). $\underline{\text { Crossref }}$

14. A.E. Volkov, M.E. Evard, E. N. Iaparova. Mater. Today: Proc. 4 (3), 4631 (2017). Crossref

15. M.E. Evard, A.E. Volkov. J. Engn. Mater. Technol. 121 (1), 102 (1999). Crossref

16. A.E. Volkov, M.E. Evard, E. N. Iaparova. MATEC Web Conf. 33, 02006 (2015). Crossref

17. N. Resnina, S. Belyaev, A. Voronkov, A. Gracheva. Smart Mater. Struct. 25, 055018 (2016). Crossref 